\title{
Revisiting the Relevance of Collaborative Governance to Korean Public Administration*
}

\author{
Taehyon Choi**
}

\begin{abstract}
Skepticism as to the relevance of collaborative governance theory and practice is often found in the literature on Korean public administration. It is not always clear, however, why and how collaborative governance is irrelevant. The purpose of this paper is to revisit the relevance of collaborative governance theory to South Korean public administration from the perspective of statelessness of the United States via three theoretical approaches: descriptive and explanatory, normative, and instrumental. Although collaborative governance can generate desirable public values related to participatory democracy, this paper suggests that if we are to apply the practice to Korean public administration, we need to develop an empirical theory of collaborative governance that incorporates the characteristics of a strong state and an instrumental theory of collaborative governance that explicitly considers group dynamics within the indigenous culture. To do this, furthermore, we first need to consider the degree to which Korean civil society appreciates the values related to collaborative governance.
\end{abstract}

Keywords: collaborative governance, statelessness, theory, comparative, state

\section{INTRODUCTION}

Interest in collaborative governance from both a theoretical and practical point of view has grown in recent times in the United States as well as South Korea. Collaborative governance is considered to be a way of solving chronic social conflicts among diverse stakeholders, of formulating local development plans or environmental protec-

* An earlier version of this paper was presented at the Public Management Research Conference, Seoul, June 30-July 1, 2014. The author thanks three anonymous reviewers for their helpful comments in the revision of this manuscript. The author also thanks Yong-duck Jung for his inspiration for this line of research in Korea.

** Taehyon Choi is an assistant professor of public policy and administration in the Graduate School of Public Administration at Seoul National University. E-mail: taehyon@snu.ac.kr.

Manuscript received July 10, 2014; out for review July 20, 2014; review completed August 15, 2014; accepted August 20, 2014.

The Korean Journal of Policy Studies, Vol. 29, No. 2 (2014), pp. 21-41.

(C) 2014 by the GSPA, Seoul National University 
tion policies through self-organization among stakeholders in a creative, deliberative, and mutually beneficial way (Thomson \& Perry, 2006). In collaborative governance, participants such as social actors and governments are treated as equal and autonomous (Booher, 2004), and collective decisions are made not by voting but through consensus (Chambers, 2003). In short, collaborative governance is an avenue through which participatory democracy is achieved in the area of social conflict, local development, and environmental protection.

What has attracted theoretical interest in collaborative governance is the question of whether the ideal of collaborative governance developed uniquely in Western societies and in the United States in particular is universally applicable across countries with different political cultures and levels of democratization; in particular, whether the inherent nature of collaborative governance, which is characterized by weakened government power in decision making, or "steering," and by enhanced citizen participation, is acceptable to countries with a history of a strong state and administrative power (Jung, 1996). Obviously, this is a variation of the traditional question from comparative politics with regard to policy and political system transfer (Dolowitz, 2004; Michael, 2004; Peters \& Pierre, 2010).

The United States has been described as a "stateless" country, meaning that the U.S. Constitution does not prescribe any specific form of public administration and bureaucratic system (Stillman, 1990; Waldo, 1980). In establishing a whole new country, the founders of the U.S. Constitution sought to design a government with limited, checked, and balanced power (Rohr, 1986). Although the United States has also gone through an "administrative state" era (Majone, 1997; Schick, 1970), the ideal of the Constitution still remains the same. Collaborative governance, which emphasizes citizens' self-determination and self-governance, is in this sense quite consistent with the statelessness of the U.S. Constitution in that it does not put strong government at the center of governance. However, the adoption of collaborative governance in other state-oriented countries such as South Korea has been understood mainly from the perspective of improving democracy or mitigating negative aspects of bureaucracy (Park \& Lee, 2009; Yoo \& Hong, 2005). More importantly, although previous research has sought to investigate the process through which collaborative governance in South Korea unfolds and the factors that affect the success and failure of collaborative governance (e.g., Chae \& Kim, 2009; Cho, Roh, \& Seoung, 2009; Eun, 2010; Kim, 2011; Yoo \& Hong, 2005; Yoon, Jung, \& Jeong, 2011), the question of what theoretical development is necessary for collaborative governance to be better employed to solve social conflicts and facilitate local development in those countries has not always been clearly addressed. In summary, what is lacking is a systematic understanding of the relevance of collaborative governance theory in terms of its descriptive and explanatory 
power in analyzing current practices of governance, the public values the theory advocates, and how to engage in collaborative governance.

The purpose of this paper is to explore the relevance of collaborative governance theory to South Korean public administration from the perspective of statelessness. Although collaborative governance can be understood from the perspective of participatory democracy or a new form of governance, for the practice to be successfully implemented, we need to consider the institutional and historical context of public administration in the country in which the ideal of collaborative governance is being attempted. Specifically, I argue that statelessness is the key characteristic in understanding collaborative governance from a comparative perspective. From the perspective of statelessness, I evaluate the relevance of collaborative governance theory in more detail according to three aspects of a social theory: descriptive and explanatory, normative, and instrumental (Bailey, 1968; Jung, 2001).

This study aims to contribute to the literature in three ways. First, I provide an overall analytical framework with which to revisit collaborative governance theory. Research on collaborative governance frequently employs the case study method; each case study alone is not enough to develop an overarching perspective on collaborative governance theory. Through the framework, we can develop a better understanding of the relevance of collaborative governance theory. Second, I focus on the concept of statelessness to assess the relevance of collaborative governance theory to Korean public administration, highlighting in particular the influence of the public law system in limiting the flexibility of public administration and the capacity of civil society, which are necessary conditions of collaborative governance. Finally, I approach collaborative governance theory in three different ways: via descriptive and explanatory theory, normative theory, and instrumental theory, which allows a systematic exploration of the theoretical components that have in place in understanding and applying collaborative governance in South Korea.

In the following section, I provide a brief summary of the concept of statelessness as defined by Richard Stillman II and the statelessness of U. S. public administration. Next I discuss collaborative governance theory as a descriptive and explanatory, normative, and instrumental public administration theory. Then, I consider the contextual difference between the United States and South Korea, focusing on statelessness in the application of collaborative governance. Finally, I consider the relevance of collaborative governance theory to Korean public administration by revisiting collaborative governance theory from a descriptive and explanatory, normative, and instrumental perspective, respectively, with respect to the contextual difference. I specifically highlight how collaborative governance theory needs to be modified or strengthened so as to improve its relevance to Korean public administration. Figure 1 summarizes the 
Figure 1. Analytical Framework for Revisiting the Relevance of Collaborative Governance Theory to Korean Public Administration

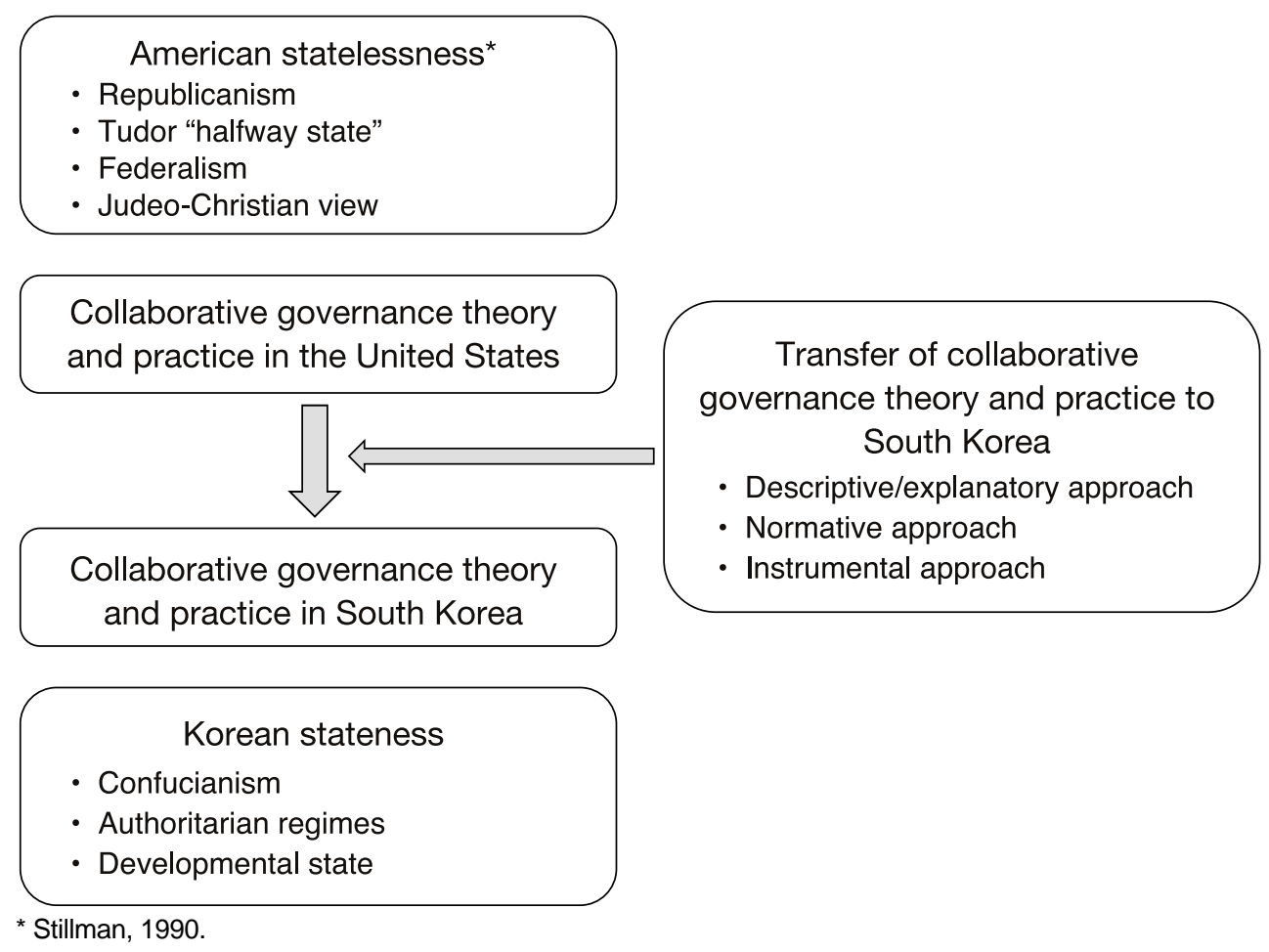

analytical framework through which this paper organizes the discussion about the relevance of collaborative governance to Korean public administration. I conclude by calling for the theoretical development of a model of collaborative governance that takes the characteristics of a strong state into account in describing collaborative governance, that can provide culture-specific managerial tools to facilitate group dynamics, and that reflects public values citizens embrace.

\section{THE STATELESSNESS OF U.S. PUBLIC ADMINISTRATION}

In his investigation of the constitutional status of public administration in the United States, Stillman (1990, p. 158) claimed that the distinct characteristic of American public administration is that it is "stateless": 
"State" simply means concrete national institutions, their laws, functions, structures, and people that carry out basic activities common to all modern nations such as tax collection, business regulation, national defense, public education, and social welfare programs. . . "Stateless" or "statelessness" is the opposite condition, namely the absence of all or most essential elements of laws, structures, functions, and people that run modern government for public purposes.

Stillman also identified four sources of statelessness: the dominant faith in republicanism, the ancient Tudor "halfway state," federalism, and classical Judeo-Christian beliefs that legitimize statelessness. According to Stillman (1990, p. 163), these sources of statelessness fashioned "an awkward, clumsy design," and they "hardly fit together consistently or formulate a rational plan for a political community." Stillman concludes that although this "statelessness" helps promote elasticity and participation and prevent corruption, the United States is failing to develop stable administrative systems and suffers from "delay, stalemates, cross-purposes in actions, and inefficiency" (1990, p. 165).

From a comparative viewpoint, the sources of American statelessness that Stillman identified are not commonly found in countries such as South Korea (Waldo, 1980) which are called "developmental states" (Evans, 1995). Administrative reforms geared toward making governance in the United State more flexible and participatory can be understood as something that follow from the principles of the Constitution. However, these same reforms contradict the traditional political culture and institutions of "overdeveloped" states (Alavi, 1979). Collaborative governance is not an exception; it seeks a balance of power and flexibility and is grounded in a community orientation, all of which are attributes valued by American politics but not appreciated that much by "developmental" or "over-developed" countries.

\section{COLLABORATIVE GOVERNANCE}

\section{Conceptualization of Collaborative Governance}

Scholars have observed various types of public sector reforms during the past 35 years that can mainly be described as contributing to movement away from the administrative state and toward new governance (Majone, 1997; Osborne, 2006; Salamon, 2002). Traditional public administration has been giving way to new forms of governance such as new public management (Hood, 1991; Osborne \& Gaebler, 1992; Rhodes, 1997), the neo-administrative state (Jessop, 1990), the hollowed-out state 
(Milward \& Provan, 2000), and new public governance (Osborne, 2006). Whatever term is used to describe the new practices in public administration, scholars argue that an increase in citizen participation in both the decision-making phase and the policy implementation phase is key (Ansell \& Gash, 2008). Concerning the characteristics of new public governance, Osborne described "a plural state" as an entity in which "multiple inter-dependent actors contribute to the delivery of public services" and " $a$ pluralist state" as an entity in which "multiple processes inform the policy making system" (2006, p. 384).

Within this context, collaborative governance has been an emerging theoretical and practical issue in public administration because it has increasingly been adopted at the local level. The concept of collaborative governance usually refers to "a group of interdependent stakeholders, usually from multiple sectors, who work together to develop and implement policies to address a complex, multi-faceted problem or situation" (Choi \& Robertson, 2014, p. 495). Institutional settings, at the center of which lies collaboration between government and citizens, have different labels, such as new public governance (Osborne, 2006), network governance (Provan \& Kenis, 2008), collaborative planning (Innes \& Booher, 2010), cross-sector collaboration (Bryson, Crosby, \& Stone, 2006), and collaborative public management (O'Leary \& Vij, 2012). O'Leary and Vij have pointed out, however, that it is not always clear what exactly we mean by "collaborative public management" and hence what we mean by "collaborative governance." Thus there are a couple of theoretical issues that need to be addressed in defining collaborative governance, specifically from a perspective that takes into account the role that the concept of the state plays in such governance.

First, it is not always clear whether collaborative governance should incorporate policy decision making as well as implementation by actors other than the government. While some scholars have focused on the collaborative implementation phase in what Milward and Provan (2000) call the hollow state, more recent views suggest that the essence of collaborative governance is collective decision making (Ansell \& Gash, 2008; Emerson, Nabatchi \& Balogh, 2012). That is, collaborative governance is not simply governance that incorporates citizens and private sector organizations as service deliverers in policy implementation or as advisors, information providers, and audience in policy decision making, which is often the case in many weak types of citizen participation; rather, it is conceptualized as a type of governance that includes features of deliberative democracy, such as dialogue and consensus-based decisions among stakeholders (Futrell, 2003; Roberts, 2002).

Second, there is no agreement on the role of government in collaborative governance. A cautious approach to collaborative governance points out a discrepancy between representative democracy and collaborative governance (cf., O’Leary \& Vij, 
2012), the institutional and psychological inertia of public administration and administrators in resisting or hesitating to accept the practice (Termeer, 2009), and the ongoing pivotal role government plays even in a form of collaborative governance like resource mobilization (Purdy, 2012). By contrast, a more radical approach to collaborative governance emphasizes its self-organizing or adaptive nature (Folke, Hahn, Olsson, \& Norberg, 2005) in which government is merely one of many actors (Rhodes, 1996). This view denies that the government plays a central role in problem solving and argues that one of the strengths of collaborative governance is its adaptive capacity that enables it to cope with complex social problems (Folke et al., 2005). Although government can still remain a key actor in successful resource mobilization and the facilitation of collaboration (Purdy, 2012), it is more a convener than a controller in an ideal collaboration.

\section{Collaborative Governance Theory in the United States}

There is no one theory of collaborative governance; instead, there are different perspectives, frameworks, and prescriptions. In this section, I review collaborative governance theory as developed in U.S. public administration literature against the backdrop of statelessness by way of reference to descriptive and explanatory, normative, and instrumental theories.

\section{Collaborative Governance: A Descriptive and Explanatory Approach}

A descriptive and explanatory theory of public administration aims to describe, explain, and predict social facts (Bailey, 1968). There is a huge chasm between positivism and hermeneutics with respect to the concept of fact (Bernstein, 1976). Positivism believes that we can uncover facts through empirical examination. By contrast, the hermeneutic approach argues for the importance of trying to understand human perception, motivation, and the meaning of behavior (Bernstein, 1976). Studies on collaborative governance are mixed in terms of methodology. A number of studies in the positivistic vein are based on the case study method; the research in these studies focuses on the institutional design of collaborative governance and on how successful collaborative stakeholder interactions are. Studies that adopt a more hermeneutic approach seek to understand human perceptions such as those that guide the process of developing a shared understanding and trust. Accordingly, as a descriptive and explanatory theory, collaborative governance theory tries to describe what really happens in collaboration and what factors contribute to the success of collaborative governance: that is, how people perceive social problems, how they interact or are organized, what 
decisions are made, how they are implemented, and what the effect of collaboration is.

The emergence of collaborative governance as a subject in public administration literature has been fueled by many successful cases reported by scholars and practitioners. Their case studies have taken mainly a descriptive and explanatory approach to collaborative governance. For example, Connick (2006) described in detail the Sacramento Area Water Forum, including its beginnings, its structure and processes, participants, and conversations, and explored factors that seemed to have contributed to its success, including facilitative leadership, social learning, the collaboration of participants who possessed resources, and government involvement in decision making. Based on such cases, a number of scholars have proposed models outlining the characteristics of collaborative governance and developed theoretical frameworks (e.g., Ansell \& Gash, 2008; Bryson et al., 2006; Emerson et al., 2012).

Although collaborative governance theory has laid claim to an empirical ground by developing a descriptive and explanatory theory, there is some skepticism about its generalization. For example, Thompson (2008) reviewed reports of many unsuccessful collaborative cases, particularly from the deliberative democracy perspective. In this view, collaborative governance (and its success) is still more of an exception than the rule in the United States, and the explanation of the factors that are thought to make successful collaboration possible is not generalizable.

\section{Collaborative Governance: A Normative Approach}

A normative theory of public administration addresses public values such as public interest, equity, and accountability, as well as criteria with which to measure the relative importance of various public values and how to choose one to pursue (Bailey, 1968). In other words, a normative theory of public administration attempts to answer the question of which public values are desirable or preferred.

A normative approach to collaborative governance argues that collaborative governance is a way to facilitate deliberative democracy, allow informed citizens to make policy decisions, solve chronic social problems, build mutual trust among stakeholders, provide opportunities for social learning, and devise creative solutions (Innes \& Booher, 2010; Roberts, 2002; Thomson \& Perry, 2006). That is, collaborative governance is proposed as an ideal alternative to a "voting-centric democracy" because it provides a feasible public administration practice for a "talk-centric democracy" (Chambers, 2003). This view presupposes that deliberative, participatory governance can produce more public values than traditional public administration can. There is little criticism of this normative approach to collaborative governance. One caveat pertains to the social costs of collaborative governance: implementing a policy by building consensus 
among various stakeholders whose interests conflict severely with each other is so costly that collaborative governance should be used only when the benefit from the practice exceeds the cost (Innes \& Booher, 2010). However, skepticism with respect to collaborative governance is not generally aimed at the normative values it seeks to produce but its practicality.

\section{Collaborative Governance: An Instrumental Approach}

An instrumental approach to public administration focuses on the "how to" question; that is, the methods, tools, and strategies required to realize public goals (Bailey, 1968). For example, leaders in collaborative governance need knowledge about how to organize stakeholder groups in terms of size, interests, and decision-making procedures and with respect to what kind of collaboration structure would be best given the nature of the social problem at hand, the stakeholders involved, and resources available (Gastil \& Levine, 2005). An instrumental approach is key to public administration as an applied social science to the extent that it helps practitioners get things done. It differs from a descriptive or explanatory approach in two respects. First, an instrumental approach tends to be adopted when there is an explicit concern with prescription or problem solving. An empirical theory may inform the development of an instrumental theory, but the former does not explicitly aim at prescribing a policy or method of management. Second, an instrumental approach depends on both an empirical and a normative theory to answer the "how to" question, which is inevitably value driven and requires scientific knowledge. An instrumental approach should be considered as important as the other approaches because descriptive and normative public administration theories by themselves cannot enhance public values; we also need methods and strategies to solve the social problems we face.

Collaboration literature has provided diverse strategies for encouraging collaboration and collective decision-making processes that can be applied to collaborative governance practices in general. For example, Gastil and Levine (2005) edited a book on strategies for effective civic engagement such as public deliberation, consensus conferences, planning cells, citizen juries, and town meetings. Similar approaches can be found in Wondolleck and Yaffee (2000) in the field of natural resource management collaboration and in Crosby and Bryson (2005) in the field of leadership. These approaches overlap with a descriptive and explanatory approach to some degree because scholars have attempted to find techniques and methods to manage collaboration by looking at practices that have been successful; however, their explicit purpose is to provide practical knowledge on the management of collaborative governance.

The next question is how statelessness might affect the relevance of the collaborative 
governance theories. In the following section, I compare the contextual backgrounds of the United States and South Korea, showing how the differences in those backgrounds mean that sophisticated theoretical consideration is required if collaborative governance theory is to be relevant to Korean public administration.

\section{CONTEXTUAL BACKGROUND OF COLLABORATIVE GOVERNANCE: A COMPARISON}

That the nature of collaborative governance is controversial is not surprising given that collaborative governance is a form of governance that has only recently emerged in areas that generally had previously been regulated by government. There are variant institutional forms of collaborative governance; in addition, collaborative governance in many cases is self-organizing rather than prescribed ex ante. From a comparative perspective, the concept of statelessness may play a pivotal role in developing a sophisticated collaborative governance theory that could be applicable to different political communities. The concept of statelessness calls to our attention a constitutional arrangement for regulating the organization of state power that embraces legal flexibility, which is critical to the success of collaborative governance, and the selfgoverning capacity of civil society. Accordingly, in this section I briefly compare the role of the concept of the state in the United States and South Korea as a backdrop to understanding collaborative governance.

\section{Organization of State Power and Public Administration}

The U.S. Constitution, according to Stillman, is "mostly silent on the subject of public administration" (1990, p. 156). Instead, it is understood to focus on establishing an institutional setting for ensuring checks and balances among powers. Stillman (1990) argued that the founders of the United States attempted to build a country in which no power could dominate; the founders' concern was not with the efficiency of power or state administration but with distributing power among different groups so that no one group emerged as dominant forever. Under the U.S. Constitution, public administration has enjoyed a significant amount of flexibility, whether it was intended or unintended (Stillman, 1990), even in the period of the "administrative state" era (Rohr, 1986). However, there has been little attention paid in the public administration literature to the question of how the U.S. Constitution and the thriving of collaborative governance are related.

By contrast, the South Korea Constitution clearly states the power and responsibility 
of the president and public administration in the chapter on the executive branch (chapter 4), which comes after the chapter on the National Assembly but before that on the judicial branch. In addition, the Constitution calls for the formation of local governments by law and outlines the responsibilities of local governments (chapter 8). Accordingly, Korean public administration is tightly regulated by public administration law at both the national and local level.

In addition, the historical institutionalization of Korean public administration has never realized checks and balances as in the United States (Jung, 2014). Public administration in South Korea has enjoyed relatively unbalanced power based on the Constitution, history, and culture from the legacy of the Chosun dynasty and the Japanese occupation to military governments from the 1960s to the 1980s. Scholars argue that this institutionalization has been supported by Confucian hierarchical culture and the mission of developmental states (Evans, 1995; Hood, 1998; Weiss, 1998).

A strong state tradition in Korean public administration has made control, not collaboration, the common practice of governance. Flexibility in the design of public administration is quite limited by the legal structure under the Continental law system. It should be noted that this difference between the United States and South Korea in their respective legal systems sets a fundamental boundary for collaborative governance. Institutional flexibility in terms of decision-making authority, resource mobilization and sharing, and accountability is key to the development and success of collaborative governance, and many scholars use concepts such as self-organization, networking, and adaptive management to describe collaborative governance or similar practices (Folke et al., 2005). Considering that collaborative governance requires a flexible design that weaves together governmental actors and civic actors, along with their authority and responsibility, the U.S. Constitution and its historical institutionalization provide a better constitutional context for collaborative governance than do the Korean Constitution and its historical institutionalization.

\section{Capacity of Civil Society}

Another huge difference between the United States and South Korea is the capacity of their respective civil societies. It is often argued that Korean civil society is not as mature as American civil society in that it is still organized in a state corporatist way; there are not enough civic organizations, and citizens are accustomed to a hierarchical and authoritarian political culture (Jung, 2014; Yoo \& So, 2005).

According to Stillman (1990), republicanism and the Judeo-Christian ideal that prefers citizens' self-governance to a central government with a planning authority, have contributed to the statelessness of American public administration. These two 
ideals express explicit distrust in a strong central government that possesses authority to regulate people's freedom or trample on their self-determination. Regardless of whether American civil society in fact has this kind of self-determining capacity (Carpini, 2004), the political ideal demonstrated in statelessness presupposes a strong, mature civil society.

By contrast, there is no tradition of modern republicanism in South Korea; indeed, until the 20th century, the country had always been a monarchy. Secondly, Confucianism, unlike the Judeo-Christian tradition, puts high trust in leaders (Park, 2009); only a "good person," who disciplines himself and his family, can be a leader according to the Confucian ideal. This kind of characteristic is not found among laypeople.

One noteworthy issue concerns the effect of social capital. There is increasing worry about the eroded capacity of civil society in the United States owing to decreased social capital, crony capitalism, and the polarization of political opinions (Nye, Zelikow, \& King, 1997; Putnam, 1993); however, this worry is not directly related to the success of specific collaborative governance, which is usually considered as a last resort when conflicts among stakeholders cannot be resolved in other ways (Connick, 2006). That is, the mutual trust among stakeholders that is critical to the success of collaborative governance is usually formed by collaborative governance itself (Ansell \& Gash, 2008; Futrell, 2003), not provided by general social capital.

In summary, the nature of the Korean state with respect to the organization of state power, design of public administration, and the capacity of civil society is such that it does not as readily support the practice of collaborative governance as does its American counterpart. This contextual difference between the United States and South Korea thus raises the question of the relevance of collaborative governance to Korean public administration. In the next section, I discuss this issue in more detail.

\section{REVISITING COLLABORATIVE GOVERNANCE THEORY}

Given that Korean public administration institutions do not provide as good a soil for collaborative governance as the United States does, in order to evaluate the relevance of collaborative governance to Korean public administration we revisit the theory of collaborative governance by reviewing the literature on collaborative governance in South Korea according to descriptive and explanatory, normative, and instrumental approaches, respectively. 


\section{Collaborative Governance: A Descriptive and Explanatory Approach}

Korean scholars have questioned whether collaborative governance theory has a place in the context of current Korean public administration (Hong \& Lee, 2009; Kang, 2002; Yoo \& So, 2005). There is no agreement on the usefulness of collaborative governance theory as a way of describing even the most recent changes in Korean public administration, particularly at the local level.

\section{Perception}

Yoo and So (2005) compared citizens' perceptions about the influence of diverse actors from the public and private sectors in the United States and South Korea and found that Koreans perceive local government to be the most influential actor regardless of policy areas, while Americans have more divergent views. Based on this finding, they concluded that in South Korea the major public administration paradigm is still based on hierarchy rather than on a network. Similarly, Jeong (2009) explored the perception of public employees in local government with respect to collaboration at the local level and found that local government leaders still remain the most influential actors in initiating collaboration and making decisions. So (2003) studied the perceptions of local government employees in the United States, Japan, and South Korea. He found that in Japanese and Korean local governance the influence of the central government remains strong and that the system of local government is more centralized than in the United States.

\section{Role of Government}

In addition to documenting the perception that government remains the major actor in local governance, many empirical studies have also highlighted Korean public sector organizations as pivotal actors in initiating, organizing, facilitating, and controlling collaboration, for example, in the project of relocating the Korean armed forces' defense security command (Moon \& Kim, 2006), local social service networks (Kang, 2002), and local development (Hyun \& Jun, 2008). They underscore that local government rather than citizens' participation, social learning, and consensus-based decision making is crucial to the success of collaborative governance (Kang, 2002; So, 2003). Although some scholars have reported cases demonstrating successful networking among civic actors, social learning among them, and the achievement of policy goals (Bae, 2002; Eun, 2010; Kim, 2011; Yoo \& Hong, 2005), even in these cases governmental actors are regarded as central actors. These findings imply that although collab- 
orative governance theories predict that the role of government in such governance should be small, evaluations of collaborative governance in South Korea need to carefully measure both the positive and negative effects of the active role played by governmental actors.

In conclusion, the theoretical framework of collaborative governance that has been developed based on American circumstances may need to be revised to describe the practice of collaborative governance in South Korea and explain its successes and failures. The legacy of the strong state in Korea puts governmental actors at the center of governance, even in collaborative governance. This implies first that collaborative governance theory in South Korea needs to consider the role of government in initiating collaboration, designing institutional arrangements for collaboration, leading the collaboration process, and building mutual trust among stakeholders. Second, given that Korean public administration is tightly regulated by the Constitution and public laws, collaborative governance theory based on the concepts of self-organization, facilitative or emergent leadership, and mutual consensus needs to be applied cautiously in the Korean context.

\section{Collaborative Governance: A Normative Approach}

As for collaborative governance from a normative viewpoint, there seems to be little disagreement even from skeptics on the desirability of public values that can be facilitated by collaborative governance, including more egalitarian decision making, deliberation, participation, citizen education, and local autonomy. Scholars who have studied severe social conflict in South Korea recently have called for the adoption of collaborative governance as a method of solving social conflict (Cho \& Kim, 2009; Jung, 2010; Kim, 2011). In the public administration literature on collaborative governance in the United States, collaborative governance is usually treated as a normative, ideal form of governance that can resolve social conflict related to local development and environmental protection (Innes \& Booher, 2010). In short, scholars seem to accept collaborative governance as desirable in both countries.

Although collaborative governance is accepted as normatively attractive in both countries, however, the practice has more complicated nuances in South Korea where a strong state has traditionally prevailed. One of the most important questions for a normative collaborative governance theory is whether the public values such a theory seeks to realize are acceptable to citizens. There has been no serious discussion regarding the acceptability of public values collaborative governance produces among Korean citizens in the literature. In particular, the cost of collaborative governance (Innes \& Booher, 2010), mainly dedicated to social learning, trust building, and consensus 
formation, may be deemed unacceptable when stakeholders are accustomed to more hierarchical and judicial coordination mechanisms. Moreover, citizens and public employees may have different views on desirable public values (Termeer, 2009). Simply put, administrative values such as efficiency, effectiveness, stability, and legal accountability are not always compatible with participatory values such as deliberation, diversity among stakeholders, self-governance, balance of power, and equity (Chambers, 2003; Peters, 1996). Only when both citizens and public employees embrace participatory public values can collaborative governance be acceptable both as a mechanism to resolve social conflicts (consequence) and as a desirable process through which public decisions are made (process).

In conclusion, careful examination of the extent to which Korean civil society and government value participation, self-governance, deliberation, and equity over efficiency, stability, and controllability is warranted.

\section{Collaborative Governance: An Instrumental Approach}

Group dynamics is an important topic in the literature on collaborative governance. For example, many books and articles on collaborative governance written by scholars and practitioners provide "toolkits" outlining managerial practices that can work to mobilize people, motivate them to share their ideas and concerns, develop a shared understanding of the issues at stake, and facilitate negotiation and collective decisionmaking processes (Crosby \& Bryson, 2005; Gastil \& Levine, 2005). Collaborative governance practitioners benefit from this extensive literature detailing instrumental theories.

A problem with regard to collaborative governance theory in South Korea is that there has been little research on the applicability of those instrumental theories to collaborative governance in South Korea. In other words, there is a paucity of knowledge as to whether those instrumental theories fit well into Korean political culture. For example, facilitative leadership that encourages participants to open their minds and share their ideas and interests is key for success in collaborative governance (Ansell \& Gash, 2008). For such a leadership approach to be effective, people have to embrace horizontal coordination. Since in South Korea coordination is frequently made vertically by political and government leaders, there is little evidence that facilitative leadership executed by actors other than government has been crucial to the success of collaboration.

A second problem is that there has been little research in the Korean public administration literature on indigenous managerial instruments that might contribute to successful collaboration. Scholars have focused on how to design institutions to facilitate 
collaboration (e.g., Eun, Kim, \& Choi, 2011); however, group dynamics through which trust building, mutual learning and consensus formation occur is still a black box (Thomson \& Perry, 2006) in the Korean public administration literature. For example, leaders have traditionally been idealized when they do something by themselves before others come to see it as necessary or desirable (Park, 2009). In other words, leaders are not so much facilitators who recognize and organize knowledge and resources already available among citizens as they are teachers or rulers who show the way. In this sense, leadership is treated not as an endogenous but an exogenous variable in the collaboration process. Instrumental theories developed in the United States usually assume the former leadership, while the latter is often ignored.

In conclusion, for collaborative governance theory to be relevant to Korean public administration, it needs to be equipped with indigenous instrumental theories that incorporate group dynamics among heterogeneous stakeholders. As Mendelberg (2002) pointed out, it is easier to create institutional settings that foster collaborative governance than it is to change stakeholders' attitudes.

\section{CONCLUSION}

In this paper, I have discussed the relevance of collaborative governance theory from the perspective of statelessness, drawing on three approaches: descriptive and explanatory, normative, and instrumental. Although collaborative governance is seen as desirable by South Korean scholars, it is debatable whether collaborative governance theory is compatible with Korean public administration. My conclusion is that although collaborative governance can generate desirable public values related to participatory democracy, for the theory to be better applied to Korean public administration, we need to develop an empirical theory of collaborative governance that incorporates the characteristics of a strong state and an instrumental theory of collaborative governance that considers diverse group dynamics including, for example, the Confucian view of leaders. As Huxham and Vangen (2005) and Purdy (2012) found, government power can be exercised in different arenas and in different ways. A descriptive and explanatory theory of collaborative governance, therefore, may benefit from developing a sophisticated model that analyzes government power and behavior in its various guises. As for an instrumental theory, practitioners need to be equipped with knowledge about, for example, how to facilitate group deliberation by setting agendas and decision rules, manage participants attendance and keep them apprised, build trust by organizing retreats, site visits, and social events, and educate stakeholders by inviting experts. An instrumental theory of collaborative governance that is sensitive to cultural 
traditions on these practices is warranted. Finally, we need first to pursue an answer to the question of how much Koreans appreciate the values related to collaborative governance.

Revisiting the relevance of collaborative governance can serve to revive the issue of policy and political system transfer between countries, which is one of the traditional issues in comparative politics and public administration (Almond, 1989). This paper contributes to the literature by examining the relevance of collaborative governance to South Korea, whose own governance is built on the tradition of a strong state.

\section{REFERENCES}

Alavi, H. 1979. The state in post-colonial societies: Pakistan and Bangladesh. New Left Review, 74(1): 59-81.

Almond, G. A. 1989. The civic culture: Political attitudes and democracy in five nations. Sage.

Ansell, C., \& Gash, A. 2008. Collaborative governance in theory and practice. Journal of Public Administration Research and Theory, 18(4): 543-571.

Bae, E. H. 2002. The relationship between local governments and local environmental NGOs: The logic of development vis-à-vis the logic of environmental protection. Korean Public Administration Review, 36(1): 253-274.

Bailey, S. 1968. Objectives of the theory of public administration. In J. Charlesworth (ed.), Theory and practice of public administration: Scope, objectives and methods (pp. 128-39). Philadelphia: American Academy of Political Science.

Bernstein, R. J. 1976. The restructuring of social and political theory. Philadelphia: University of Pennsylvania Press.

Booher, D. E. 2004. Collaborative governance practices and democracy. National Civic Review, 93(4): 32-46.

Bryson, J. M., Crosby, B. C., \& Stone, M. M. 2006. The design and implementation of cross-sector collaborations: Propositions from the literature. Public Administration Review, 66: 44-55.

Carpini, M. X. D., Cook, F. L., \& Jacobs, L. R. 2004. Public deliberation, discursive participation, and citizen engagement: A review of the empirical literature. Annual Review of Political Science, 7: 315-44.

Chambers, S. 2003. Deliberative democratic theory. Annual Review of Political Science, 6: 307-26.

Chae, J., \& Kim, J. 2009. A study on the constitution and effectiveness of the collaborative governance in public conflict: A conflict over the location of a waste incineration 
plant in Icheon city. Korea Local Administration Review, 23(4): 107-136.

Cho, M., \& Kim, L. S. 2009. A empirical study on building cooperative governance: Focusing on case study as a big deal of environmental facilities. Korean Society and Public Administration, 20(2): 215-239.

Cho, S., Roh, J., \& Seoung, J. 2009. The study of the success factors of cooperative local governance: Centering on the case of the creation of Dohwadongsan in Jinan. Korean Journal of Local Government \& Administration Studies, 23(1): 499-522.

Choi, T., \& Robertson, P. J. 2014. Deliberation and decision in collaborative governance: A simulation of approaches to mitigate power imbalance. Journal of Public Administration Research and Theory, 24(2): 495-518.

Connick, S. 2006. Sacramento area water forum: A case study. IURD working paper series 2006-06. Berkeley, CA: University of California.

Crosby, B. C., \& Bryson, J. M. 2005. Leadership for the common good. San Francisco: Jossey-Bass.

Dolowitz, D. 2004. Bring back the states: Correcting for the omissions of globalization. In D. Levi-Faur and E. Vigoda-Gadot (eds.), International public policy and management: Policy learning beyond regional, cultural and political boundaries (pp. 25-44). New York: Marcel Dekker.

Emerson, K., Nabatchi, T., \& Balogh, S. 2012. An integrative framework for collaborative governance. Journal of Public Administration Research and Theory, 22(1): 1-29.

Eun, J. 2010. Public accountability in collaborative governance: Lessons from Korean community centers. Korean Journal of Policy Studies, 25(1): 143-173.

Eun, J., Kim, H., \& Choi, D. 2011. Military facility siting conflicts in Korea: Lessons from Jeju naval post construction case. Korean Policy Studies Review, 20(2): 319-352.

Evans, P. B. 1995. Embedded autonomy: States and industrial transformation. Princeton: Princeton University Press.

Folke, C., Hahn, T., Olsson, P., \& Norberg, J. 2005. Adaptive governance of socialecological systems. Annual Review of Environment and Resources, 30: 441-473.

Futrell, R. 2003. Technical adversarialism and participatory collaboration in the US chemical weapons disposal program. Science, Technology \& Human Values, 28(4): 451-482.

Gastil, J., \& Levine, P. 2005. The deliberative democracy handbook. San Francisco: Jossey-Bass.

Hong, S. M., \& Lee, J. W. 2009. Deliberative governance for consensus building and institutional design. Korean Journal of Public Administration, 47(1): 21-44. 
Hood, C. 1991. A public management for all seasons? Public Administration, 69(1): 3-19.

Hood, C. 1998. The art of the state: Culture, rhetoric, and public management. New York: Oxford University Press.

Huxham, C., \& Vangen, S. 2005. Managing to collaborate: The theory and practice of collaborative advantage. New York: Routledge.

Hyun, K., \& Jun, Y. S. 2008. A comparative case study on the establishment of local governance due to the community development policy of the central government: Focusing on the Gwang-Myeong city's Gwang-Myeong station revital movement case and the Chung-Ju city's public enterprise invitation movement case. Korean Journal of Policy Analysis and Evaluation, 18(1): 293-325.

Innes, J. E., \& Booher, D. E. 2010. Planning with complexity: An introduction to collaborative rationality for public policy. New York: Routledge.

Jeong, M. 2009. A study of collaborative governance in local economic development. Korean Public Administration Review, 43(3): 229-250.

Jessop, B. 1990. State theory. Cambridge, UK: Polity Press.

Jung, Y. 1996. The 'statelessness' of American public administration and its impact on development of Korean public administration. Korean Journal of Public Administration, 34(1): 33-50.

Jung, Y. 2001. Public administration in the modern state. Seoul: Bobmunsa.

Jung, Y. 2010. Introduction to studies on public conflicts and policy coordination. Korean Journal of Public Administration, 48(4): 1-30.

Jung, Y. 2014. The Korean state, public administration, and development: Past, present, and future challenges. Seoul: Seoul National University Press.

Kang, C. 2002. Regional governance and the delivery of welfare services: A network approach. Korean Public Administration Review, 36(2): 313-332.

Kim, H. 2011. An application of collaborative governance model in the nuclear waste siting processes of Gyungju. Governmental Studies, 17(2): 143-182.

Majone, G. 1997. From the positive to the regulatory state: Causes and consequences of changes in the mode of governance. Journal of Public Policy, 17(2): 139-167.

Mendelberg, T. 2002. The deliberative citizen: Theory and evidence. In M. X. D. Carpini, L. Huddy, \& R. Shapiro (eds.), Political decision making, deliberation and participation, 6th ed. (pp. 151-93). Greenwich, CT: JAI Press.

Michael, B. 2004. The globalization of anticorruption policies. In D. Levi-Faur and E. Vigoda-Gadot (eds.), International public policy and management: Policy learning beyond regional, cultural and political boundaries (pp. 325-349). New York: Marcel Dekker.

Milward, H. B., \& Provan, K. G. 2000. Governing the hollow state. Journal of Public 
Administration Research and Theory, 10(2): 359-380.

Moon, C., \& Kim, K. 2006. Developing a collaborative governance system: Focusing on the relocation project of defense security command. Journal of Korea Planners Association, 41(6): 177-193.

Nye, J. S., Zelikow, P., \& King, D. C. 1997. Why people don't trust government. Cambridge, MA: Harvard University Press.

O'Leary, R., \& Vij, N. 2012. Collaborative public management where have we been and where are we going? American Review of Public Administration, 42(5): 507-522.

Osborne, D., \& Gaebler, T. 1992. Reinventing government: How the entrepreneurial spirit is transforming government. Reading, MA: Addison-Wesley.

Osborne, S. P. 2006. The new public governance? Public Management Review, 8(3): 377-87.

Park, B. 2009. Leadership in Eastern history. In J. W. Hong and J. S. Hahm (eds.), National competitiveness and leadership (pp. 14-52). Seoul: Bobmunsa.

Park, H. J., \& Lee, I. 2009. Regional development policy tool and formation of collaborative governance: Winning coalition model approach to formation of regional partnership. Korean Policy Studies Review, 18(2): 7-35.

Peters, B. G. 1996. The future of governing: Four emerging models. Lawrence: University Press of Kansas.

Peters, B. G., \& Pierre, J. 2010. Economic crisis, public administration, and governance. Korean Journal of Policy Studies, 25(1): 59-71.

Provan, K. G., \& Kenis, P. 2008. Modes of network governance: Structure, management, and effectiveness. Journal of Public Administration Research and Theory, 18(2): 229-252.

Purdy, J. M. 2012. A framework for assessing power in collaborative governance processes. Public Administration Review, 72(3): 409-417.

Putnam, R. D. 1993. The prosperous community. American Prospect, 4(13): 35-42.

Rhodes, R. 1997. Understanding governance: Policy networks, governance, reflexivity and accountability. Buckingham, UK: Open University Press.

Roberts, N. C. 2002. Keeping public officials accountable through dialogue: Resolving the accountability paradox. Public Administration Review, 62(6): 658-69.

Rohr, J. A. 1986. To run a constitution: The legitimacy of the administrative state. Lawrence: University Press of Kansas.

Salamon, L. M. 2002. The tools of government: A guide to the new governance. New York: Oxford University Press.

Schick, A. 1970. The cybernetic state. Society, 7(4): 14-26.

So, S. C. 2003. Local power structure in Korean, Japanese, and American local 
governments. Korean Journal of Local Government Studies, 15(3): 337-362.

Stillman, R. J. 1990. The peculiar 'stateless' origins of American public administration and consequences for government today. Public Administration Review, 50(2): 156-167.

Termeer, C.J.A.M. 2009. Barriers to new modes of horizontal governance. Public Management Review, 11(3): 299-316.

Thompson, D. F. 2008. Deliberative democratic theory and empirical political science. Annual Review of Political Science, 11:497-520.

Thomson, A. M., \& Perry, J. L. 2006. Collaboration processes: Inside the black box. Public Administration Review, 66(s1): s20-s32.

Waldo, D. 1980. The enterprise of public administration. Novato, CA: Chandler and Sharp

Weiss, L. 1998. The myth of the powerless state. Ithaca, NY: Cornell University Press. Wilson, W. 1887. The study of administration. Political Science Quarterly, 2(2): 197-222. Wondolleck, J. M., \& Yaffee, S. L. 2000. Making collaboration work. Washington, D.C.: Island Press.

Yoo, J., \& Hong, S. 2005. Multi-level governance blossoming in the era of government: A case study of the cooperative management of water resource among the governments and the local residents in Korea. Korean Political Science Review, 39(2): 171-194.

Yoo, J., \& So, S. C. 2005. Government or governance? Hierarchies or networks? Korean Public Administration Review, 39(1): 41-63.

Yoon, E., Jung, G., \& Jeong, M. 2011. A study of factors influencing actors' collaboration in network governance in community service center. Korea Local Administration Review, 25(4): 129-154. 